\title{
Examination of Social Justice Behaviors: Testing an Integrated Model
}

Tuyet Mai Ha Hoang

University of Illinois

Helen A. Neville

University of Illinois

V. Paul Poteat

Boston College

Lisa B. Spanierman

Arizona State University

\begin{abstract}
In this study, we tested an integrated model of social justice behaviors among a community sample of 179 Asian American and White American adults. The integrated model builds on the theory of planned behavior (TPB) and sociopolitical development theory (SPD). Findings from path analyses provided partial support for the integrated model. Specifically, social justice awareness, subjective norms, and perceived behavioral control were uniquely and positively related to participants' social justice intention. Intention to act, however, did not predict self-reported social justice behaviors. Multiple group comparison analyses suggested that the aspects of the integrated model consistent with the TPB were better supported in the White American sample, whereas the aspects of the model consistent with SPD were a better fit for the Asian American sample. Particularly, social justice attitudes were related to self-reported actions for Asian Americans in the sample, but not White Americans.
\end{abstract}

Key Words: Social justice; critical consciousness; theory of planned behavior; sociopolitical development; Asian American; White American.

(C) 2020 Hoang, Neville, Poteat, \& Spanierman. Free to copy and share for education and scholarship under a Creative Commons Attribution NonCommercial-NoDerivatives 4.0 License. 


\section{Examination of Social Justice Behaviors: Testing an Integrated Model}

The current political climate in the United States continues to be highly polarized during the COVID-19 pandemic and Black Lives Matter movement for racial justice. The volatile social climate has been linked to increased hate crimes directed at racial, ethnic, and religious minorities (Duncan \& Hatzenbuehler, 2014; Samson, 2015), shootings in El Paso, TX (ABC News, 2019) and Pittsburgh, PA (The New York Times, 2018), and higher level of discrimination toward Black and Asian American during COVID-19 (Ruiz et al., 2020). These hate crimes reveal the persistence of racism as a major problem in society (Neal, 2017, August 29). Scholars have proposed that in a time of crisis and pain, developing critical consciousness - the personal awareness of systemic inequality (critical awareness) and taking action (Freire, 1970; Watts et al., 2011) - can help heal and empower people who experience oppression (Ginwright, 2011). Understanding ways to foster social awareness and behaviors is important for two reasons: (1) critical awareness can promote system-level changes against injustices (Freire, 1970; Martín-Baró et al., 1994; Watts et al., 2003), and (2) social justice actions can foster healing and hope in marginalized populations (Ginwright, 2011; Watts et al., 1999).

The commitment to social justice is described as a core value in all aspects of the counseling profession, including clinical services, prevention, outreach, teaching, and research (Goodman \& West-Olatunji, 2009; Ratts et al., 2016). Although a number of theories outline dimensions of social justice, there is limited quantitative data supporting such theories. One area of social justice theory that does have emerging empirical support is critical consciousness, which helps to guide the inquiry of the current research. The purpose of this study is to better understand the association between social justice attitudes and actions. Counseling scholars have begun to explore how people develop better social awareness and activism, specifically to enhance multicultural training, foster protective factors, and support the well-being of marginalized populations (Shin et al., 2016). In this study, we extend this emerging area of research by testing a model of how social justice attitudes might predict individuals' actions against injustice. To this end, we rely on the theoretical frameworks of the theory of planned behavior (TPB; Ajzen, 1991) and sociopolitical development (SPD; Watts et al., 1999). We test our model among White Americans because allies are needed to take action to challenge racial inequality, and also among Asian Americans because their involvement in social action has been sizable yet understudied. Below, we define critical consciousness and two theoretical frameworks for SPD. The current study relies on this literature to create our conceptual model.

\section{Critical Consciousness and Theories of Social Behaviors}

\section{Critical Consciousness}

The conceptualization of critical consciousness has its roots in educational philosophy. Critical consciousness, or "conscientizacao," is a term coined by Freire (1970) through his literacy work with Brazilian farmers. He described critical consciousness as a process where oppressed individuals achieve understanding of systemic inequality shaping their social conditions and, in turn, take action to challenge the root causes of their oppression (Freire, 1970; Watts et al., 2011). Although this concept has been applied in education, philosophy, and psychology, the current project focuses on critical consciousness in the context of SPD. Critical consciousness from a SPD framework consists of two main components: critical reflection and critical action (Diemer et al., 2014; Prilleltensky, 2012). Critical reflection refers to an analysis and understanding of sociopolitical and systemic inequality, such as social, economic, and political conditions that limit access to opportunity and perpetuate injustice (Diemer \& Li, 2011; Watts \& Flanagan, 2007). Critical action refers to participation in individual or collective efforts to change aspects of society, such as unjust institutional policies and practices (Watts et al., 2011; Watts \& Flanagan, 2007).

The link between critical reflection and action would benefit from greater empirical attention (Pillen et al., 2020; Watts et al., 2011). It is important to notice that the literature of critical consciousness guides our 
research inquiry, but the current study focuses specifically on understanding how social justice awareness can lead to social justice behaviors. Thus, our research questions are as follows: Are adults higher in social justice awareness more likely to engage in social justice behaviors? And what psychological mechanisms underlie the association between social justice attitudes and actions? This project extends previous research by exploring the link between individuals' attitudes about social justice and the psychological mechanism that leads to their actions by testing an integrated model that builds on principles of the TPB and SPD.

\section{Theory of Planned Behavior}

Learning how an individual moves from social justice values/attitudes to action can be understood through Ajzen's (1991) TPB. We draw from TPB because it is a well-supported framework designed to explain how individuals' beliefs can lead to actual behavior. Moreover, the TPB model has been adapted when developing a scale to explore social justice attitudes and intentions (Torres-Harding et al., 2012). This scale provides an opportunity to apply the TPB framework to understand individuals' social justice awareness and actions.

TPB states that one's behavior is best predicted by one's intention to act, while intention is determined by three other variables: one's attitudes towards the behavior, subjective norms around the behavior, and one's perceived behavioral control (Ajzen, 1991). Intention is considered the motivational component that spurs an individual to engage in or exert effort to try a particular behavior (McEachan et al., 2011). Attitudes toward the behavior refers to individuals' evaluation, positive or negative, based on their understanding of the behavior in question (Ajzen, 1991). Subjective norms refer to perceived social pressure to perform or not to perform the behavior based on social norms or expectations (Ajzen, 1991). Perceived behavioral control represents the individual's capacity and efficacy based on the perceived ease or difficulty of performing the behavior, and it is assumed to reflect past experience as well as anticipated obstacles (Ajzen, 1991). In the area of social justice, perceived behavioral control captures one's perceived capacity and efficacy to produce social change (TorresHarding et al., 2012). Thus, perceived behavioral control can be viewed as a sense of agency for social justice. The TPB model designates perceived behavioral control as directly predicting one's behavior.

TPB has been applied successfully to a range of health-related behaviors with diverse populations (Close et al., 2018; White et al., 2012) and shown to have medium to large effect sizes in more than nine metaanalyses (see Ajzen, 2011). In one meta-analysis with 237 studies on health-related behaviors, McEachan et al. (2011) found the intention-behavior correlation to have a moderate effect size (.43) and the perceived controlbehavior correlation to have a lower effect size (.31). McEachan and colleagues also found that the correlations of attitudes, subjective norms, and perceptions of control with intention ranged from .40 to .57 .

\section{Theory of Sociopolitical Development}

Along with TPB, we selected the theory of SPD because it was developed based on Freire's (1970) concept of critical consciousness (Watts et al., 1999; Watts et al., 2003). SPD is the process of how "individuals acquire the knowledge, analytical skills, emotional faculties, and the capacity for action in political and social systems necessary to interpret and resist oppression" (Watts et al., 2003, p. 185). Watts and Flanagan (2007) outlined four components of SPD: (1) worldview and social analysis, (2) sense of agency, (3) opportunity structure, and (4) societal involvement behavior. Worldview and social analysis measure one's critical reflection and awareness of social inequity. Sense of agency is an overarching variable referring to theoretical constructs such as empowerment, sociopolitical control, and efficacy (i.e., self, collective, or political). Opportunity structure speaks to the accessibility that individuals have to participate in civic action or social activism. In this framework, sense of agency and opportunity structure are hypothesized to moderate the individual's commitment and action for social justice. Finally, societal involvement behavior captures one's commitment and critical action to address social oppression and injustices.

There is some support for the SPD model. For example, Watts and Guessous (2006) found that critical 
social analysis, sense of agency, and cultural worldview had direct effects on intention for societal involvement, but they did not predict actual behaviors. Their findings also provided support for the moderating role of agency, such that the positive association between belief in an unjust world and societal involvement behavior was particularly important for those who endorsed a high sense of agency but not for those who endorsed a low sense of agency. At lower levels of experience of agency, the relationship was reversed; viewing the world as unjust was negatively related to behavior (Watts \& Guessous). These findings have been replicated more recently. For example, Bañales et al. (2019) found an association between critical consciousness and self-reported antiracism action in interpersonal relationships and in politics in a sample of racially diverse teenagers.

\section{The Integrated Model of Social Justice Action}

Although researchers have applied SPD in their conceptualization of social justice action, the association between social justice awareness and actions and potential mediators (e.g., sense of agency and opportunity structure) remains uncertain (Watts et al., 2011). Additionally, there is mounting evidence supporting the TPB model in understanding social behavior, but there is little empirical study using TPB to investigate social justice actions (Torres-Harding et al., 2012). This study is one of the first investigations to apply both components of the TPB model and SPD conceptualization to understand the psychological process for individuals to engage in social justice self-reported behaviors.

In the current study, we integrated two process-models to capture the concept of social justice action: the general TPB and the explicit social justice framework of SPD. This study tested an integrated model of social justice actions (see Model A in Figure 1). Model A in Figure 1 outlines the TPB framework which shows the pathways of social justice attitudes (path c), subjective norms (path d), perceived behavioral control (path e) going through intention to act (path g) in accounting for self-reported social justice behaviors. TPB also suggests the direct relationship between perceived behavioral control and behaviors (path $\mathrm{f}$ ). SPD provides further insight that individuals' social justice attitudes have a direct relation to their social justice behavior (path b). In addition, SPD delineates the moderation effect of perceived behavioral control on the relationship between social justice attitudes and self-reported social justice behaviors (path a). In summary, the integrated model thus assesses the potential mediating role of one's intention to act on the association between social justice attitudes, subjective norms, and perceived behavioral control on self-reported social justice actions (path c, d, e, and g) based on the TBP framework. The integrated model also assesses for the moderation effect of perceived behavioral control and social justice attitudes (path a), as well as the direct effect of social justice attitudes on social justice behaviors (path b).

\section{Figure 1. Models of Social Justice Behaviors}

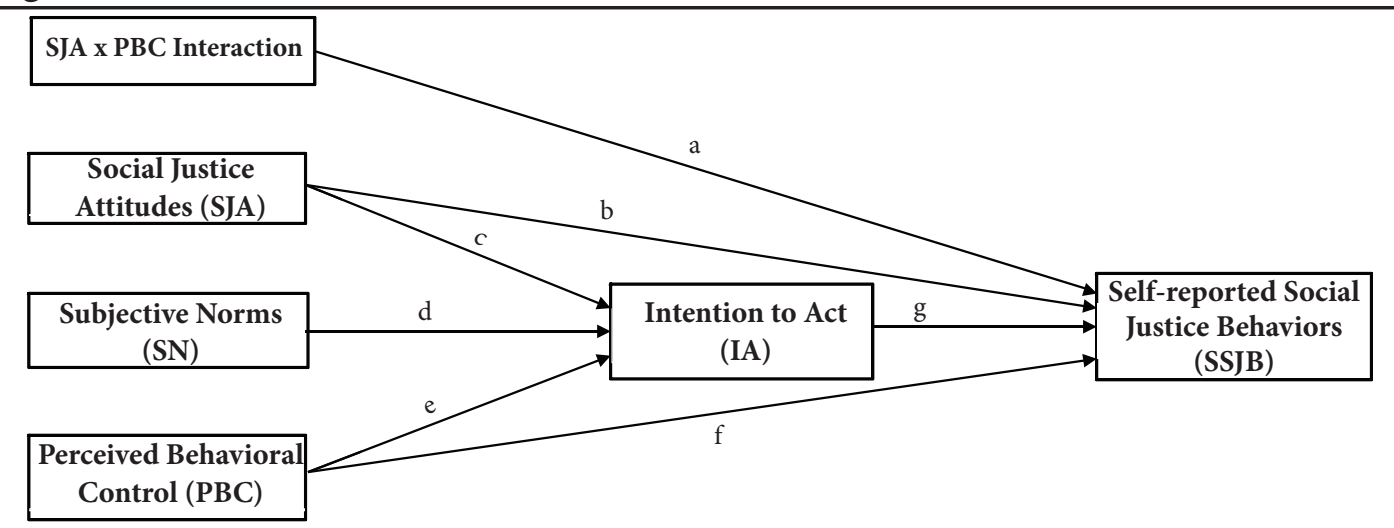

Note: Model A is the integrated model of social justice behaviors. It includes all the paths. Model B is the full model without the SJA $x$ PBC interaction. It includes paths b, c, d, e, f, and g. Model C is the model without the SJA x PBC interaction and the direct effect of PBC to SSJB. Model C includes paths b, c, d, e, and g. 


\section{Social Justice Action among Asian Americans and White Americans}

The term Asian American has been used as an umbrella or pan-ethnic expression to describe both U.S. citizens and immigrants who trace their roots to Asia; but, this term often misleads people to view Asian Americans as a monolithic, single political and social group (Shih et al., 2019). In reality, Asian Americans differ in their immigration history, resettlement patterns and experiences, socioeconomic status, experiences of oppression, cultural values and beliefs, and ethnic identity (Shih et al., 2019). In addition, elite powerful White Americans have racially framed the "model minority" stereotype - which describes traits of hardworking, successful, and law-abiding ethnic minorities - to Asian Americans (Chou \& Feagin, 2016). This stereotype camouflages the psychological consequences and systematic inequality that Asian Americans face (Alvarez et al., 2006). More importantly, the "model minority" stereotype often leads others to assume that Asian Americans do not experience difficulties and/or are problem-free, thus leaving them out of social justice research (Shih et al., 2019).

COVID-19 has laid bare not only current but a long history of stigma and discrimination against Asian Americans, while also uncovering a clear lack of attention to their notable contributions and involvement in social justice work (Le et al., 2020). With the rise in hate incidents and xenophobic attitudes toward Asian descents during the global pandemic (Ruiz et al., 2020), more attention turned to Asian Americans'social change behaviors. In particular, scholars began to examine the ways in which Asian Americans address racism and also their responses to the Movement for Black Lives (Lang, 2020). Surprisingly, there is little research in this area. Research on social justice action generally focuses on Black and Latinx populations in the United States and very few published studies have included Asian American samples. The limited research shows mixed findings in understanding Asian Americans' actions to make social change in their communities (Lin, 2020). The "model minority" stereotype again often leads people to perceive Asian Americans as unengaged in social activism; however, social activism among Asian Americans, like all Americans, varies based on developmental context, background, and demographics (Choi, 2014; Wray-Lake \& Tang, 2016).

Although there are few studies on Asian Americans' social justice behaviors, emerging data shows that Asian Americans have increasing levels of civic engagement. For example, as a pan-ethnic group, Asian Americans have significantly increased their voter turnout from 2000 to 2016 (Igielnik \& Budiman, 2020) and in the 2020 election, Asian American voters helped to win key battleground states such as Georgia (Benk \& Garcia-Navarro, 2020). More recent research also showed that Asian American college students actively engaged in social change behaviors (Kuo et al., 2017; Yi \& Todd, 2020).

Furthermore, Kwon's (2008) ethnographic study examined the process of critical consciousness among 100 Asian and Pacific Islander activists in California. He found that their process of critical consciousness development began with critical analysis of their lived experiences with inequalities followed by collective and political activism (Kwon, 2008). Analyzing qualitative and quantitative data from the California Young Adult Study, Lin (2018) found that participating in youth organizing groups helped Asian Americans connect these types of lived experiences with racism to larger social structures. She further described the role of youth organizing groups in promoting increased awareness around race and racism among Asian American young adults.

Although critical consciousness was originally conceptualized for people who are oppressed, this construct also can be applied to dominant groups, such as White Americans (Diemer et al., 2015). History provides examples of individuals who reject their privilege and become allies (Watts et al., 2003). In the United States, civil rights and social movements in the 1960s or more current movements, such as Black Lives Matter or Marriage Equality, often involve support and advocacy from dominant group members. Research also supports the point that awareness of White privilege and understanding of systemic inequality are associated with individuals' social action in their daily lives, as well as professional or clinical practices (Ancis \& Szymanski, 2001; Bott, 2013; Neville et al., 2006). Lewis, Neville, and Spanierman (2012), for example, found that White university students who acknowledged the structural nature of racism and possessed greater awareness of the role of race in 
shaping the experiences of racial and ethnic minorities were more likely to support policies to promote greater access to college to students from historically underrepresented backgrounds. Specifically, White students who participated in a greater number of campus diversity experiences were more likely to support affirmative action (Lewis et al., 2012). Although there is research on critical consciousness among White Americans, this line of inquiry has remained limited (Diemer et al., 2015). It speaks to the need for further research for this population to support future White counselors and allies more broadly in their ability to act as an agent of social change, to address issues of oppression, and to promote well-being (Malott et al., 2019).

\section{Hypotheses}

Consistent with the literature on TPB and SPD that serves as the foundation for our integrated model of social justice action, we hypothesized the following:

1. Higher levels of social justice attitudes, perceived behavioral control, and favorable subjective norms would be related to stronger intention to act in support of social justice causes (testing path $\mathrm{c}, \mathrm{d}$, and e in Figure 1).

2. Based on the logic of TPB, greater perceived behavioral control and stronger intention to act for social justice would have positive associations with self-reported social justice behaviors (testing path $\mathrm{f}$ and $\mathrm{g}$ in Figure 1).

3. On the basis of SPD theory, social justice attitudes would be positively related to self-reported social justice behaviors (testing path $\mathrm{b}$ in Figure 1).

4. Also based on SPD, perceived behavioral control would moderate the association between individuals' social justice attitudes and self-reported social justice behaviors (testing path a in Figure 1).

We compared slightly different integrated social justice action models to determine which aspects of the model were the best fit of the data (see Figure 1). Finally, for exploratory purposes we examined if the paths in our models differed significantly across Asian American and White American participants in our sample.

\section{Method}

\section{Participants}

Participants were 179 (112 White American and 67 Asian American) college alumni from a large Midwestern university. Data were part of a larger longitudinal study; these data were part of a 12-year followup study. For White Americans, roughly half of the sample was women $(50.9 \% ; n=57)$ and $49.1 \%$ was men $(n=55)$. The mean age of White American participants was 30.05 years $(S D=.23)$. For Asian Americans, approximately $58.2 \%$ of the sample was women $(n=39)$ and $41.8 \%$ was men $(n=28)$. The mean age of Asian American participants was 30.08 years $(S D=.62)$. In the Asian American sample, $26.6 \%$ of people self-identified as Chinese $(n=17), 20.3 \%$ was Korean $(n=13), 18.8 \%$ was Indian $(n=12), 9.4 \%$ was Filipino $(n=9), 7.8 \%$ was Taiwanese $(n=5), 2.9 \%$ was Japanese $(n=2), 2.9 \%$ was Pakistani $(n=2), 2.9 \%$ was Thai $(n=2), 1.4 \%$ was Sri Lankan $(n=1)$, and $5.9 \%$ were missing data on ethnicity $(n=4)$. Asian American participants were born in the United States and/or were American citizens. All participants completed at least a four-year college degree.

\section{Measures}

Demographic information. Participants provided demographic information regarding their age, gender, race, and ethnicity.

Social Justice Scale (SJS). The 24-item Social Justice Scale (SJS; Torres-Harding et al., 2012) is rated on a Likert-type scale, with 1 (strongly disagree) to 7 (strongly agree), and consists of four subscales: social justice attitudes, perceived behavioral control, subjective norms, and behavioral intention. The scale was designed 
specifically to capture social justice attitudes and intention from TPB and is consistent with critical reflection as described in the SPD mode of social justice action. The SJS was used to measure the four main constructs in the integrated model of social justice behavior: (1) attitude and awareness of social justice values, (2) subjective norms about social justice issues, (3) perceived behavioral control of social justice action, and (4) intention to act for social justice causes. Higher scores on each subscale reflects higher levels of the construct of interest.

The social justice attitudes subscale (11 items) measures one's attitudes/awareness toward social justice values (e.g., "I believe that it is important to make sure that all individuals and groups have a chance to speak and be heard, especially those from traditionally ignored or marginalized groups"). The subjective norms subscale (4 items) assesses whether people in the respondents' social context support or discourage engagement in social justice-related activities (e.g., "Other people around me are engaged in activities that address injustices"). The perceived behavioral control subscale (5 items) measures individuals' perceived capacity and efficacy in creating social change through their actions (e.g., "If I choose to do so, I am capable of influencing others to promote fairness and equality"). Lastly, the behavioral intention subscale consists of 4 items (e.g., "In the future, I will do my best to ensure that all individuals and groups in my community have a chance to speak and be heard").

There is emerging psychometric support for the SJS among young adult and adult populations. In terms of convergent validity, all of the responses to the social justice subscales were positively correlated with the motivation to engage in public services, and for discriminant validity, the responses to the social justice subscales were negatively correlated with neo-sexism, symbolic racism, and one's global belief-in-a-just-world (TorresHarding et al., 2012). In addition, the social justice attitudes subscale had Cronbach's alphas ranging from .87 (Branson, 2015) to .95 (Torres-Harding et al., 2012). Perceived behavioral control had Cronbach's alphas ranging from .66 (Kozlowski et al., 2014) to .84 (Torres-Harding et al., 2012). Subjective norms had Cronbach's alphas ranging from .81 (Kozlowski et al., 2014) to .82 (Torres-Harding et al., 2012), and behavioral intention had a Cronbach's alpha of .88 (Kozlowski et al., 2014; Torres-Harding et al., 2012). For the current study, Cronbach's alphas ranged from .86 (perceived behavioral control) to .93 (social justice attitudes).

Self-reported social justice behavior. Social justice behavior was measured by participants' decision to sign one or two online petitions at the end of the survey. We chose signing petitions as an indicator of social justice behavior because this action could be done immediately compared to other offline behaviors such as protesting or boycotting, which would take time and effort to follow-up. Moreover, given that social media and internet have increased visibility and access to social justice movements, such as Me Too or Black Lives Matter, online petitions have become an important tool to mobilize collective power toward larger social changes (Mele, 2016). Additionally, emerging data indicates that online activism is related to more direct offline activism (Greijdanus et al., 2020). Directions explained that these two petitions were chosen from Change.org among established causes and they did not necessarily reflect the researchers' opinions. Signing the Change. org petition(s) was an indication that they were in agreement with the cause and that they were willing to join with others to symbolically show support for the issue. In the survey, we provided the exact description of the petitions and provided a link for the participants to sign the petition. Participants were also asked whether they would sign or abstain from signing the petitions. The first petition called for criminal justice reform in the United States and lower incarceration rates, particularly for young people of color (Jones, 2016). The second petition gathered support to fight for a higher minimum wage (The Fairness Project, 2016). Each petition was coded with 0 (signed) or 1 (not signed).

\section{Procedure}

The Institutional Review Board granted approval to for our data collection. Updated email addresses were obtained for a random racially diverse sample of alumni $(n=1047)$ in the same cohort from the university online database. Participants' responses were confidential and their names were not listed on the survey. Potential participants were emailed a recruitment letter and code number for identification. For alumni who did not respond to the first email invitation, two other follow-up emails were sent at approximately one-week intervals. 
For those who chose to participate, they completed a consent form, which explained the purpose of the study and a request to respond to two social issues at the end of the survey. The online survey took approximately 15 minutes to complete and participants were asked whether they would like to sign two Change.Org petitions. Survey items were randomly organized while demographic questions and two online petitions were presented at the end of the survey. Participants who completed a majority of the items on the survey had the opportunity to enter a drawing for four Visa gift card prizes: One $\$ 500$ and three $\$ 100$ prizes. To increase the number of Asian American participants, we sent a third follow-up email to this group specifically with an additional reward option to receive a $\$ 5$ Starbucks gift card or equivalent. The final response rate was $25 \%$ for all racial groups ( $n=263$ alumni out of the total 1047). A group of 179 participants, who completed at least $80 \%$ of the survey, was selected for the project. The response rate for each group was comparable: 23\% (Asian American) and 22\% (White American).

\section{Results}

Table 1. Descriptive Statistics and Cronbach's Alphas for Variables of Interest by Race/Ethnic Group

$\begin{array}{lllllllll}\text { Variable } & 1 & 2 & 3 & 4 & 5 & M & S D & \alpha\end{array}$

\section{Total Sample $(N=179)$}

1. Social Justice Attitudes (SJA)

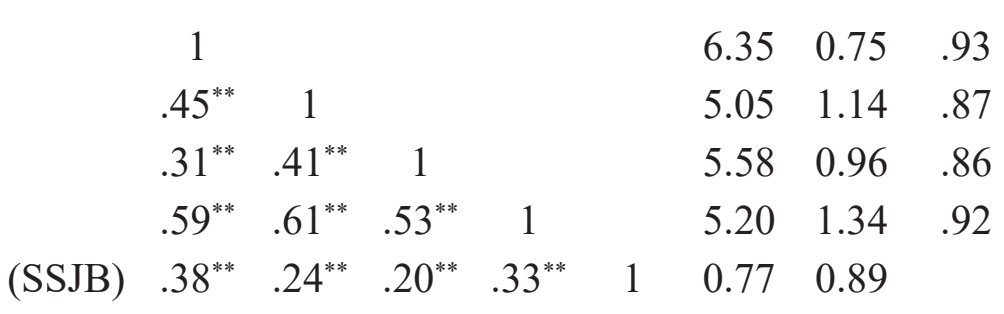

2. Subjective Norms (SN)

3. Perceived Behavioral Control (PBC)

White Sample $(n=112)$

1. Social Justice Attitudes (SJA)

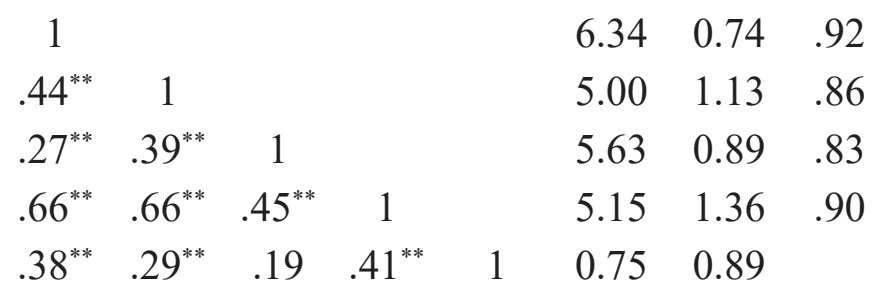

2. Subjective Norms (SN)

3. Perceived Behavioral Control (PBC)

4. Intention to Act (IA)

5. Self-reported Social Justice Behaviors

(SSJB)

\section{Asian American Sample $(n=67)$}

1. Social Justice Attitudes (SJA)

\begin{tabular}{|c|c|c|c|c|c|c|}
\hline 1 & & & & & 6.36 & 0.76 \\
\hline $.47^{* *}$ & 1 & & & & 5.15 & 1.17 \\
\hline $.36^{* *}$ & $.46^{* *}$ & 1 & & & 5.48 & 1.06 \\
\hline $.46^{* *}$ & $.53^{* *}$ & $.69^{* *}$ & 1 & & 5.30 & 1.30 \\
\hline $.38^{* *}$ & .16 & .22 & .19 & 1 & 0.81 & 0.91 \\
\hline
\end{tabular}

2. Subjective Norms (SN)

3. Perceived Behavioral Control (PBC)

4. Intention to Act (IA)

5. Self-reported Social Justice Behaviors (SSJB)

Note: Possible range for SJA, SN, PBC, IA are 1 to 7 . SSJB is ordinal categorical variable. ${ }^{*} p \leq .05 ; * * p \leq .01$. 
Table 2. Model Comparisons

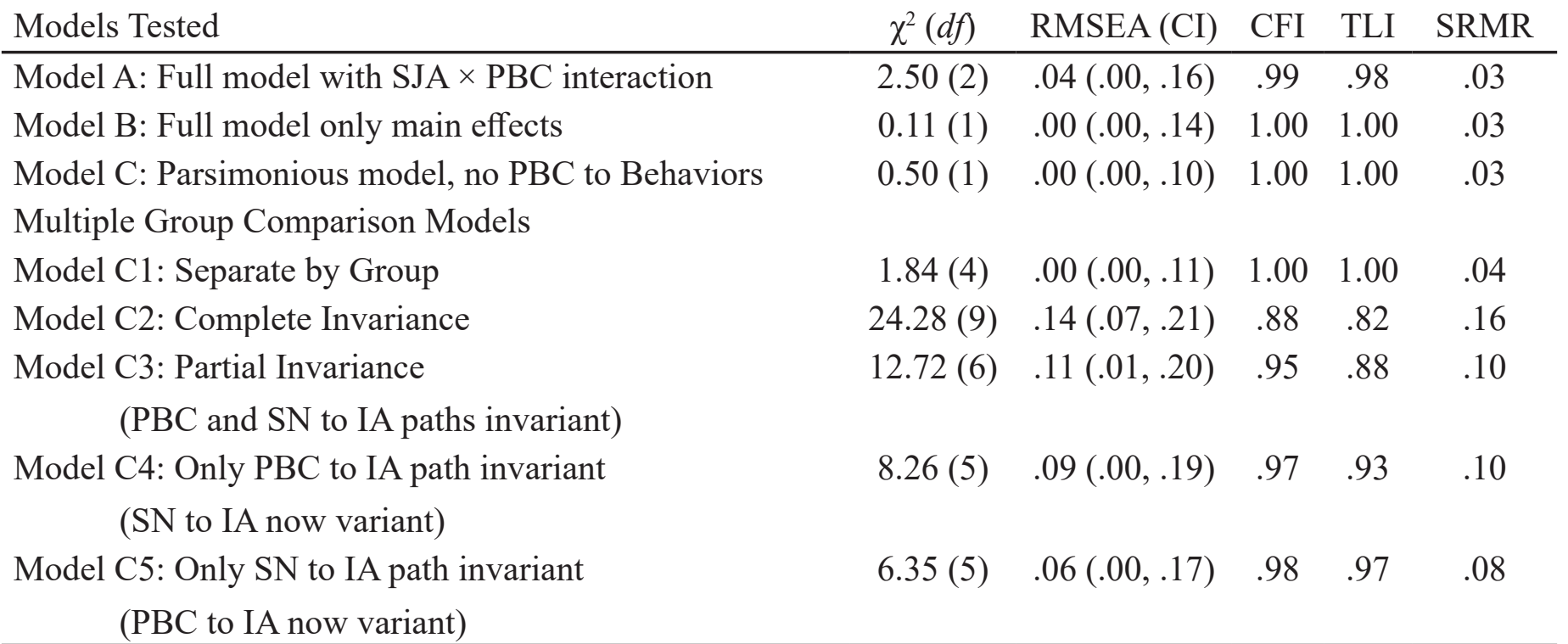

Note: SJA = social justice attitudes; $\mathrm{PBC}=$ perceived behavioral control; $\mathrm{IA}=$ intentions to act; $\mathrm{SN}=$ subjective norms. Model $\mathrm{A}$ is the full model with all paths and SJA $\times$ PBC interaction predicting behaviors. Model B is the full model without the SJA $\times$ PBC interaction. Model $C$ is the parsimonious model without the direct effect of perceived behavioral control to behaviors. Model C1 estimates Model C separately for the Asian American and White American participants. Model C2 estimates Model C with complete invariance of all paths between the Asian American and White American participants. Model C3 estimates Model C only with invariance of paths that were significant for both the Asian American and White American participants. Model C4 and C5 test for the invariance of the specific path of PBC and SN to IA, respectively, for the Asian American and White American participants. Fit indices include: $\chi^{2}$ (df), the chi-square value with corresponding degrees of freedom; RMSEA (CI), the root mean square error of approximation with $90 \%$ confidence intervals; CFI, the comparative fit index; TLI, the Tucker-Lewis Index; SRMR, the standardized root mean squared residual.

\section{Data Screening and Missing Data}

Data were cleaned and screened for univariate normality by examining histograms, skewness, and kurtosis statistics. All variables of interest met the criteria for univariate normality with normally distributed histograms, skewness $< \pm 3$, and kurtosis $< \pm 3$, which were below the guidelines suggested by Weston and Gore (2006). We detected four univariate outliers. Outliers with extreme scores were found in three cases on the social justice attitudes subscale, and one case on the behavioral intention subscale. The outliers' raw scores were changed to the next most extreme score in the distribution (Tabachnick \& Fidell, 2013) for each racial group. Additionally, seven cases were identified as multivariate outliers $(p<.001$; (Tabachnick \& Fidell, 2013). A robust estimator was used in subsequent analyses to account for non-normality.

Missing data were less than 4\% for the Asian American sample and less than 3\% for the White American sample. These data were found to be missing completely at random at the variable level (i.e., Little's MCAR test, $p=.7247$ ) (Garson, 2015). The missing data were handled by pairwise present analysis through estimator robust weighted least squares or WLSMV (Muthén et al., 1997).

\section{Preliminary Analyses}

Roughly $41 \%(n=74)$ of 179 participants indicated that they would sign at least one of the social justice petitions: criminal justice reform $(n=67)$ and/or higher minimum wage $(n=60)$. Roughly $28 \%(n=50)$ indicated they would sign both petitions. Also, there were no significant differences between Asian American and White American samples on their commitment to sign the petitions, OR (odds ratio) $=.96, p>.05$. Zero- 
order correlations, descriptive statistics, and Cronbach's alphas for the study variables are presented in Table 1. There were small to medium positive associations between each of the study variables and self-reported social justice behaviors. Correlations ranged from .20 (perceived behavioral control) to .38 (social justice attitude).

\section{Main Analyses}

Path analysis was conducted using Mplus version 7.4 (Muthén \& Muthén, 1998-2015) and utilizing WLSMV to test the model of social justice action and our four hypotheses (see Figure 1). We chose WLSMV because it allows inclusion of both continuous and categorical variables. WLSMV with standard errors and chisquare statistics were used because they are robust to non-normality (Muthén et al., 1997).

The original integrated model of social justice action is labeled as Model A in Table 2. The overall model was a good fit of the data with partial support for the research hypotheses. Hypothesis 1 was largely supported because the direct relations among study variables were significant; that is, social justice attitudes, subjective norms, and perceived behavioral control were positively related to intention to act for social justice causes. Hypothesis 2 was not supported in that intention to act for social justice causes was not significantly associated with self-reported social justice behaviors. Also, the direct relation between perceived behavioral control and self-reported social justice behaviors was non-significant. Hypothesis 3 was supported as the finding showed that social justice attitudes were positively related to self-reported social justice behaviors (SSJB). Hypothesis 4 was not supported because the interaction term was not statistically significant $(\beta=.03, p>.05)$. Previous researchers stated that perceived efficacy and control might be a more developmentally appropriate indicator for youth in their process of developing critical consciousness, given the many age-based constraints young people face to actual civic participation or social activism (Diemer et al., 2015). Watts and Flanagan (2007) also conceptualized political efficacy as a moderator in the process of critical consciousness among marginalized youth but did not mention whether it would apply for adult population. This finding suggested that moderation and direct effects of $\mathrm{PBC}$ might not be present among adults.

Subsequently, we tested two conceptually derived, nested models. Specifically, we tested two simpler models: Model B is the original integrated model without perceived behavioral control as a moderator (see Figure 2). Model $\mathrm{C}$ is a simpler version of the integrated model without either the moderation effect or the direct effect of perceived behavioral control on self-reported behaviors. Model B and C removed the moderation effect and direct path of perceived behavioral control on self-reported behaviors respectively, because these paths were theoretically more consistent with youth development as opposed to adults (Diemer et al., 2015). We compared models based on fit indexes (Bryant \& Satorra, 2012). See Table 2 for comparisons of the alternative model to the original Model A.

\section{Figure 2. Model B of Social Justice Behaviors}

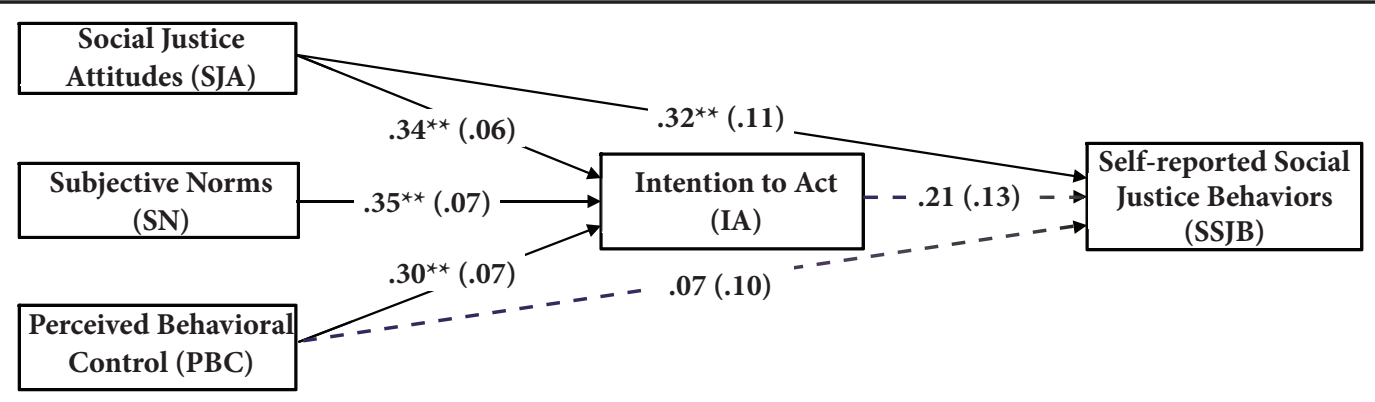

Note: ${ }^{*} p \leq .05 ;{ }^{* *} p \leq .01 ; \mathrm{SE}$ are in the parentheses. Dashed lines signify non-significant paths. Values reflect standardized parameter estimates. 
We examined four fit indexes (RMSEA, CFI, TLI, and SRMR) and followed the cutoff criteria based on recommendations to assess model fit (Asparouhov \& Muthen, 2018; Hu \& Bentler, 1998, 1999). The recommended cutoff values are: RMSEA values of .06 or below, CFI and TLI values of .95 or above, and SRMR values less than .08 (Asparouhov \& Muthen, 2018; Hu \& Bentler, 1999). RMSEA 90\% confidence interval values were also presented. However, because the sample size is less than 250, RMSEA can be problematic as it tends to over-reject true population models at small sample sizes (Hu \& Bentler, 1999).

Results indicated that the slightly revised integrated Models B and C provided a equivalently better fit to the data than Model A, and Model C was most parsimonious. Model C was the simplest model with excellent fit indexes: $\mathrm{RMSEA}=.00, \mathrm{CFI}=1.00, \mathrm{TLI}=1.00$, and $\mathrm{SRMR}=.03$. Thus, we selected Model C for our exploratory analysis to examine potential differences among White American and Asian American participants. Model C includes all of the hypothesized variables of TPB and SPD, with the exception of the moderation effect and the direct effect of perceived behavioral control on self-reported social justice behavior. The latter two effects were not significant when we tested Model A.

We used the multi-group function in Mplus to compare the model of critical consciousness for the Asian American and White American participants in the sample. Multi-group analysis used the power of the combined sample size $(N=179)$ to estimate the model parameters for each racial group (Asparouhov \& Muthén, 2012) and to determine if there were potential differences in model fit between the two groups and whether the model varied significantly for each group. In order to compare variance between the two groups, we conducted a series of steps to test different models. Each model had a discrete number of estimated parameters that were constrained to be equal in order to explore whether these parameters could not differ for Asian and White American groups. These steps are parts of the common approach (Meredith, 1993; Napolitano \& Job, 2018; Vandenberg \& Lance, 2000) to test invariance for multiple demographic groups. Step 1 was to test for configural invariance with the result demonstrated in Model C1 in Table 2. Model C1 estimated Model C separately for the Asian American and White American participants assuming that the groups had different estimated paths without equality constraints. Step 2 was to test for strong invariance in Model C2, where all the estimated paths in Model $\mathrm{C}$ were equated between the Asian American and White American participants. Step 3 was to test for weak invariance where Model C3 estimated Model C only with invariance of paths that were significant for both the Asian American and White American participants. An additional two steps were conducted in Model C4 and C5 to test for the invariance of the specific path of perceived behavior control and subjective norms to intention, respectively, for the Asian American and White American participants. Goodness of fit was examined for models C1 - C5 to determine best fit. Model C1 was selected where estimated paths were different for Asian and White American groups.

Furthermore, we also used the WLSMV's robust standard errors to create 95\% confidence intervals for the indirect relations between the independent variables of social justice attitudes, subjective norms, and perceived behavioral control and the dependent variable of self-reported social justice behavior through intention to act (see Table 3). It is recommended that if the confidence interval does not contain 0 , then it is judged to be significant at $p \leq .05$ (Mallinckrodt et al., 2006). Goodness of fit was also examined.

The estimated parameters for White and Asian American participants are presented in Figures 3 and 4. Findings among the White American participants were partially consistent with the TPB aspect of the model, in that there were direct relations between social justice attitude-intention to act, social norms-intention to act, and perceived behavioral control-intention to act. However, among the White participants, intention to act did not predict self-reported social justice behaviors. On the other hand, findings among the Asian American participants indicated support for an SPD aspect of the model, in that there was a direct relationship between social justice attitude and self-reported social justice behaviors. As indicated in Table 3, however, there were no significant indirect effects. 
Table 3. Indirect Relations

\begin{tabular}{|c|c|c|c|c|c|}
\hline & & & $\begin{array}{l}\text { Standardized } \\
\text { indirect } \\
\text { relation }\end{array}$ & $\begin{array}{c}\text { Unstandardized } \\
\text { indirect } \\
\text { relation }\end{array}$ & $\begin{array}{c}95 \% \mathrm{CI} \text { of } \\
\text { unstandardized } \\
\text { indirect relation }\end{array}$ \\
\hline Predictor & Mediator & Outcome & & $S E$ & $\begin{array}{ll}\text { Lower } & \text { Upper } \\
\text { bound } & \text { bound }\end{array}$ \\
\hline
\end{tabular}

\section{Unique Indirect Relations in Model C for Total Sample}

\begin{tabular}{|c|c|c|c|c|c|c|}
\hline $\begin{array}{l}\text { Social Justice } \\
\text { Attitudes }\end{array}$ & Intention to Act & $\begin{array}{l}\text { Self-reported Social } \\
\text { Justice Behaviors }\end{array}$ & .05 & .12 & .07 & -.002 \\
\hline Subjective Norms & Intention to Act & $\begin{array}{l}\text { Self-reported Social } \\
\text { Justice Behaviors }\end{array}$ & .04 & .08 & .05 & -.002 \\
\hline $\begin{array}{l}\text { Perceived } \\
\text { Behavioral Control }\end{array}$ & Intention to Act & $\begin{array}{l}\text { Self-reported Social } \\
\text { Justice Behaviors }\end{array}$ & .04 & .08 & .05 & -.002 \\
\hline
\end{tabular}

\section{Unique Indirect Relations in Model C for White Sample}

Social Justice

Attitudes

Subjective Norms Intention to Act

Perceived

Behavioral Control

Intention to Act

Intention to Act
Self-reported Social

Justice Behaviors

Self-reported Social

Justice Behaviors

Self-reported Social

Justice Behaviors

.15

.14

.06

\section{Unique Indirect Relations in Model C for Asian Sample}

Social Justice

Attitudes

Intention to Act

Self-reported Social

Justice Behaviors

Subjective Norms

Intention to Act

Self-reported Social

Justice Behaviors

Perceived

Behavioral Control
Self-reported Social

Intention to Act
Justice Behaviors

$\begin{array}{lllll}.02 & .03 & .15 & -.05 & .15 \\ .03 & .03 & .09 & -.06 & .14 \\ .07 & .07 & .15 & -.14 & .33\end{array}$

.33

$\begin{array}{llll}.07 & .05 & .00 & .14\end{array}$

Note: All paths are not significant with $p>.05$.

Figure 3. Model C of Social Justice Behaviors for White Americans

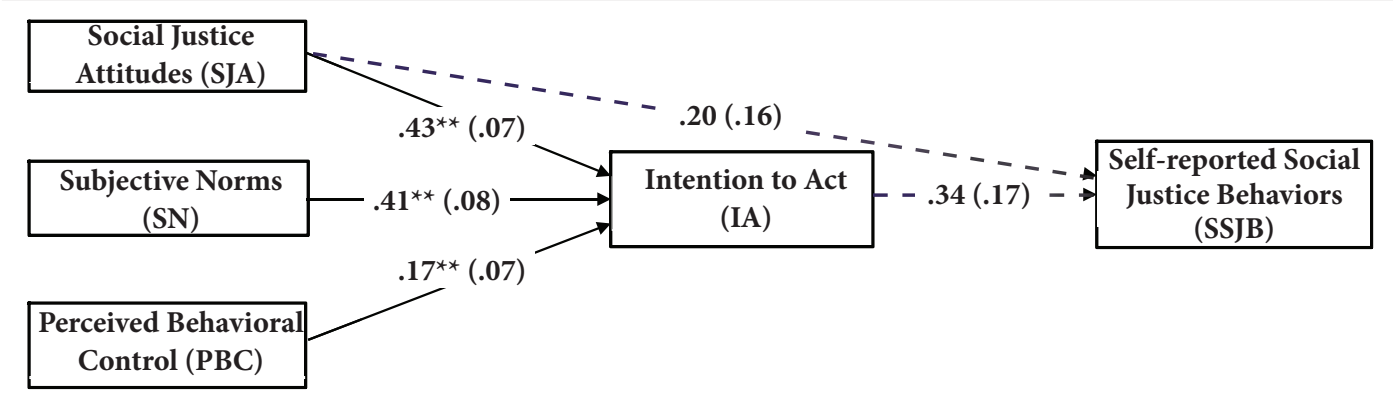

Note: ${ }^{\star} p \leq .05 ;{ }^{* *} p \leq .01 ; \mathrm{SE}$ are in the parentheses. Dashed lines signify non-significant paths. Values reflect standardized parameter estimates. 
Figure 4. Model D of Social Justice Behaviors for Asian Americans

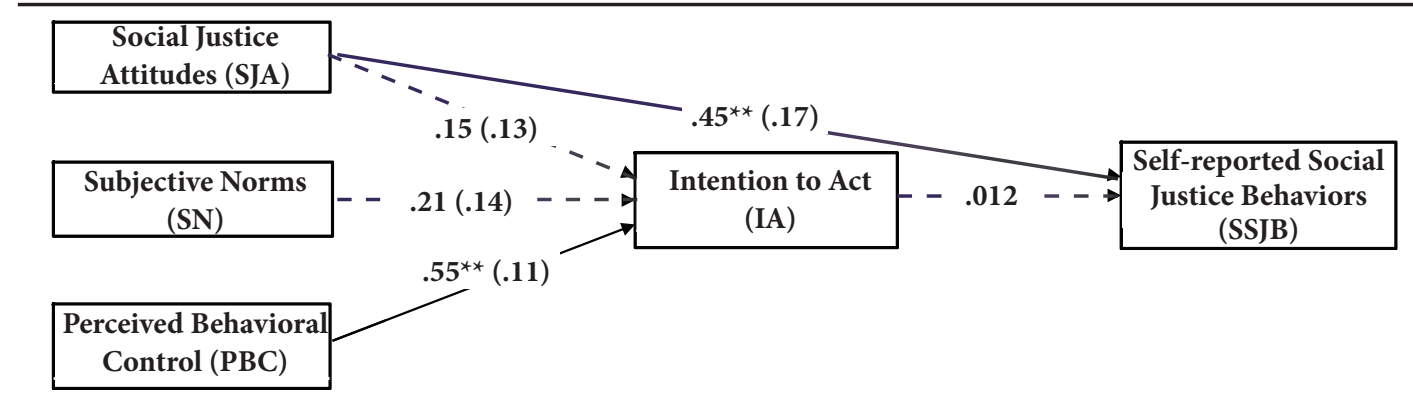

Note: ${ }^{\star} p \leq .05 ;{ }^{\star \star} p \leq .01 ;$ SE are in the parentheses. Dashed lines signify non-significant paths. Values reflect standardized parameter estimates.

\section{Discussion}

Empirical research on social justice action is receiving increased attention in counseling (Almeida et al., 2017; Byars-Winston, 2012; French et al., 2020; Malott et al., 2019; Shin et al., 2016), but the extent to which specific components of social justice frameworks predict behaviors has remained understudied, especially using TPB. Drawing on the SPD and TPB frameworks, we tested and found partial support for an integrated model of social justice action. Specifically, social justice awareness helped explain participants' signing at least one online petition addressing a public concern. Consistent with TPB, social justice attitudes, subjective norms, and perceived behavioral control were each related to participants' intention to engage in social activism. However, the latter did not serve as a mediator. In fact, unlike previous TPB meta-analyses (e.g., Ajzen, 2011; McEachan et al., 2011), there was not a significant association between intentions to act and behaviors, perhaps because the social justice behavior in this study was limited to signing online petitions.

Interestingly, findings from the exploratory multi-group analysis suggested that aspects of the integrated model consistent with the TPB framework were supported primarily among White American participants. In contrast, those consistent with the SPD model were supported more so among Asian American participants. Specifically, the links between social justice attitudes-intention, subjective norms-intention, and perceived behavioral control-intention were significant only for the White participants. In contrast, among the Asian American participants, social justice awareness was the most important predictor of social justice behavior; this association among White Americans was not statistically significant.

There are several possible reasons for why the conceptualization of critical consciousness based on TPB was a better fit for White Americans than Asian Americans in this study. Consistent with Torres-Harding et al.s (2012) research, we found that greater subjective norms and perceived behavioral control were related to participants' intention to engage in social justice behaviors. In effect, people whose social networks espoused a social justice value and those with greater political efficacy in making significant changes in their community were more likely to pledge to promote social justice through activism, including talking with others about injustices. These results imply other mechanisms may be at play in White individuals' social justice behaviors. Perhaps, racial guilt could help explain the relations between behavioral intent or past behavior and current social justice behavior (Iyer et al., 2003). Research supports the role of racial guilt over and anger about social injustices and social activism among White Americans (Iyer et al., 2003; Jost et al., 2017). Although researchers need to further investigate the potential role of racial affect such as guilt and anger in White Americans' social justice engagement, our findings, along with others (Jost et al., 2017), suggest that mediating variables may account for the association between critical awareness of inequalities and social action. In addition, the fact that the TPB model did not provide a good fit for the Asian American data highlights the possible different mechanism behind social justice actions for White and Asian Americans, at least in this sample. Previous findings showed that other factors, such as racial/ethnic identity development and individual-level perceptions of discrimination and racism, contribute to differences in level of critical awareness and social change behaviors 
among Asian Americans and subgroups (Alvarez et al., 2006; Yi \& Todd, 2020). Furthermore, Asian American participants in this study might have understood items about subjective norms and perceived behavioral control differently than White Americans. Some Asian Americans may experience different socialization processes about social activism. More Asian Americans, for example, may rely on other factors (e.g., individual experiences of discrimination, feelings of belonging) for motivation to act for social change. In the study by Yi and Todd (2020) using a sample of 3,707 Asian American students from 88 campuses across the U.S., they found multiple factors, such as participation in racial/ethnic identity-based organizations and individual-level perceptions of a discriminatory campus climate, as the mechanism behind social change behaviors of Asian American subgroups (Yi \& Todd, 2020).

The SPD framework is designed to capture the experiences of marginalized populations (Watts et al., 2003) which could be why we found support for the association between social justice awareness and social action for Asian American participants, but not for White American participants. SPD posits that as people of color gain increasing awareness of oppression they move toward engaging in social change efforts (Watts et al., 2003). From this framework People of Color are thus ultimately propelled to act in their group interests as a form of self-preservation or liberation. White Americans who benefit from racial privilege may not feel the same urgency to take action to address inequality. Instead, they may act to alleviate guilt or anger over injustices, perhaps as a way to assuage discomfort over one's relative privilege (Ivey et al., 2004). Our findings provide some initial support for these assertions. Social justice awareness served as a strong factor in promoting social action among Asian American participants only.

Contrary to our hypothesis, there were no statistically significant associations between perceived behavioral control and self-reported social justice behaviors. This result is similar to some of Diemer and Li's (2011) findings in that sociopolitical control (i.e., the perceived efficacy to effect social and political change) did not predict social action in their sample of marginalized youth. The current study replicated Watts and Guessous's (2006) finding that sense of agency was positively related to commitment to societal involvement but did not predict behaviors. There could be several explanations for these findings. It could be that signing online petitions does not adequately capture the breadth of social action in which individuals would otherwise engage. In other TPB studies, researchers administered scales that either assessed a broad set of intention and behaviors or something very specific such as the intention to stop smoking and examining this intention to actually quitting smoking (Rise et al., 2008). The matched specificity of intention and behaviors have been discussed as the concept of the correspondence (compatibility) between attitudinal and behavioral entities (Ajzen \& Fishbein, 1977). This concept suggests that all measures of behavior and TPB explanatory variables should have the same context, time, population and action (actual behavior), in order to gain the strongest relationships (effect size) between model components (Ajzen, 1991). In this study, we used a broad measure of behavioral intention (e.g., planning to talk to someone about a social justice topic in the future) and specific self-reported actions (e.g., signing online petition on criminal justice reform). A similar logic can be applied to all the measures of the social justice scale. For example, individuals' broad social justice attitudes may not reflect one's attitudes/awareness toward specific social issues listed in each petition.

\section{Limitations and Future Directions}

Although the findings begin to address gaps in the literature, the limitations of the study should be considered when interpreting the results. Due to the small sample size and specificity of the sample, there are limitations to the generalizability of our findings. The current study is limited to only two racial groups: Asian Americans and White Americans, and there was not enough diversity within the Asian American sample to explore potential ethnic group differences (e.g., Chinese Americans compared to Korean Americans). Thus, the findings may not be generalized to all Asian American subgroups. Future researchers should recruit a larger sample with more diversity within Asian American participants. It is also important to replicate these findings with more diverse samples in term of race or ethnicity, social class, and education, especially because 
all participants in the current study were college graduates. In addition, although we assessed participants' reports of signing two online petitions, we could not verify if they actually did so. Future studies should consider including multiple measures of behavior that might be directly observed (e.g., lab-based scenarios). Another limitation of this study was the use of cross-sectional data to test the integrated model of social justice action. Future research should test the mediation model with longitudinal data in order to provide more empirical understanding of the process of critical consciousness development.

\section{Implications}

Due to the positive and long-term benefits of developing one's critical consciousness, it is important for counselors, educators, and policy makers to understand psychosocial factors that contribute to the process of social justice action development. Especially under the current polarized and hostile political and social climate, fostering critical consciousness and social justice behaviors can promote systematic changes against social injustice (Freire, 1970; Martín-Baró et al., 1994; Watts et al., 2003), while nurture healing and hope in marginalized and oppressed populations (Ginwright, 2011; Watts et al., 1999). To bolster social and ally activism, counselors can create a supportive and open environment to facilitate difficult conversions about systems of inequality (e.g., race, class, and gender) to increase individuals' social justice awareness and critical reflection, which in turn may strengthen their intention to act and foster more social justice-promoting activities. It is also important to build social, communal, or personal spheres of influence that promote social justice and continue difficult but hopeful dialogues so that these messages can become positive social norms to increase individuals' activism. Moreover, subjective norms can be a powerful influence through close relationships such as friendship and mentorship to motivate one's behavior as well as bolster self-efficacy in creating social and transformative changes. We encourage future researchers and practitioners to develop and evaluate TPB-based social justice interventions for allies as well as use a SPD theoretical framework to develop interventions for People of Color. Last but not least, it may be important for educators and counselors to include a social justice agenda in their clinical and teaching approaches by continually educating and providing information about the history and current status of different systems of inequality, which can increase people's social awareness, especially among youth population (Kim et al., 2017), and in turn promote their social justice activities.

\section{Corresponding Author}

The authors declare that they have no conflicts of interest. Correspondence concerning this article should be addressed to Tuyet Mai Ha Hoang Ph.D., School of Social Work, 1010 W Nevada St, University of Illinois at Urbana-Champaign, Urbana, IL 61801 or thhoang3@illinois.edu. 


\section{References}

ABC News. (2019). Alleged shooter cased El Paso Walmart before rampage that killed 22: Law enforcement officials. https://abcnews.go.com/US/death-toll-rises-22-el-paso-shooting-victims/story?id=64780680

Ajzen, I. (1991). The theory of planned behavior. Organizational Behavior and Human Decision Processes, 50(2), 179-211. https://doi.org/10.1016/0749-5978(91)90020-T

Ajzen, I. (2011). The theory of planned behaviour: Reactions and reflections. Psychology \& Health, 26(9), 1113-1127. https://doi.org/10.1080/08870446.2011.613995

Ajzen, I., \& Fishbein, M. (1977). Attitude-behavior relations: A theoretical analysis and review of empirical research. Psychological Bulletin, 84(5), 888-918. https://doi.org/10.1037/0033-2909.84.5.888

Almeida, R. V., Dolan-Del Vecchio, K., \& Parker, L. (2017). Transformative family therapy: Just families in a just society. Boston, MA: Pearson.

Alvarez, A. N., Juang, L., \& Liang, C. T. H. (2006). Asian Americans and racism: When bad things happen to "model minorities." Cultural Diversity and Ethnic Minority Psychology, 12(3), 477-492. https://doi. org/10.1037/1099-9809.12.3.477

Ancis, J. R., \& Szymanski, D. M. (2001). Awareness of White privilege among White counseling trainees. The Counseling Psychologist, 29(4), 548-569. https://doi.org/10.1177/0011000001294005

Asparouhov, T., \& Muthén, B. (2018). SRMR in Mplus. Retrieved 08/14/2020, from https://www.statmodel. com/download/SRMR2.pdf

Asparouhov, T., \& Muthén, B. (2012). Multiple group multilevel analysis. Mplus Web Notes, 16(15), 1-45. http://www.statmodel.com/examples/webnotes/webnote16.pdf

Bañales, J., Aldana, A., Richards-Schuster, K., Flanagan, C. A., Diemer, M. A., \& Rowley, S. J. (2019). Youth anti-racism action: Contributions of youth perceptions of school racial messages and critical consciousness. Journal of Community Psychology, 1-22. https://doi.org/10.1002/jcop.22266

Benk, R., \& Garcia-Navarro, L. (2020). Asian American and Pacific Islander turnout helped hand Biden Georgia. Retrieved from https://www.npr.org/sections/biden-transitionupdates/2020/12/04/942271036/asian-american-and-pacific-islander-turnout-helped-hand-bidengeorgia

Bott, C. L. (2013). A survey-based study of social workers' critical consciousness and practice with lgb clients (Publication Number 1511553563; 2014-99050-311) [Dissertation, http://search.proquest.com. proxy2.library.illinois.edu/docview/1511553563?accountid $=14553$

Branson, C. L. (2015). Learn to swim: A mixed methods approach to understanding how social work experiential education impacts students' social justice attitudes (Publication Number ProQuest: 1779535896) [Dissertation, University of Hawai'i at Manoa]. Ann Arbor, MI. http://search.proquest. com.proxy2.library.illinois.edu/docview/1779535896? accountid=14553

Bryant, F. B., \& Satorra, A. (2012). Principles and practice of scaled difference chi-square testing. Structural Equation Modeling: A Multidisciplinary Journal, 19(3), 372-398. https://doi.org/10.1080/10705511.2 $\underline{012.687671}$

Byars-Winston, A. (2012). Broadening sources of dignity and affirmation in work and relationship. The Counseling Psychologist, 40(2), 255-267. https://doi.org/10.1177/0011000011429033

Choi, Y. (2014, March 01). Moving forward: Asian Americans in the discourse of race and social problems [journal article]. Race and Social Problems, 6(1), 1-3. https://doi.org/10.1007/s12552-014-9113-6 
Chou, R. S., \& Feagin, J. R. (2016). Myth of the model minority: Asian Americans facing racism (2nd ed.). New York, NY: Routledge.

Close, M. A., Lytle, L. A., Chen, D.-G., \& Viera, A. J. (2018). Using the theory of planned behavior to explain intention to eat a healthful diet among Southeastern United States office workers. Nutrition \& Food Science, 48(2), 365-374. https://doi.org/10.1108/NFS-06-2017-0123

Diemer, M. A., \& Li, C. H. (2011). Critical consciousness development and political participation among marginalized youth. Child Development, 82(6), 1815-1833. https://doi.org/10.1111/j.14678624.2011.01650.x

Diemer, M. A., McWhirter, E. H., Ozer, E. J., \& Rapa, L. J. (2015). Advances in the conceptualization and measurement of critical consciousness. The Urban Review, 47(5), 809-823. https://doi.org/10.1007/ $\underline{\text { s11256-015-0336-7 }}$

Diemer, M. A., Rapa, L. J., Park, C. J., \& Perry, J. C. (2014). Development and validation of the critical consciousness scale. Youth \& Society, 49(4), 461-483. https://doi.org/10.1177/0044118X14538289

Duncan, D. T., \& Hatzenbuehler, M. L. (2014). Lesbian, gay, bisexual, and transgender hate crimes and suicidality among a population-based sample of sexual-minority adolescents in Boston. American Journal of Public Health, 104(2), 272-278. https://doi.org/10.2105/AJPH.2013.301424

Freire, P. (1970). Pedagogy of the oppressed. United Kingdom: Bloomsbury Publishing.

French, B. H., Lewis, J. A., Mosley, D. V., Adames, H. Y., Chavez-Dueñas, N. Y., Chen, G. A., \& Neville, H. A. (2020). Toward a psychological framework of radical healing in communities of color. The Counseling Psychologist, 48(1), 14-46. https://doi.org/10.1177/0011000019843506

Garson, G. D. (2015). Missing values analysis \& data imputation. Asheboro, NC: Statistical Associates Publishers.

Ginwright, S. (2011). Hope, healing, and care: Pushing the boundaries of civic engagement for african american youth. Liberal Education. Retrieved from http://www.shawnginwright.com/articles/

Goodman, R. D., \& West-Olatunji, C. A. (2009). Applying critical consciousness: Culturally competent disaster response outcomes. Journal of Counseling \& Development, 87(4), 458-465. https://doi. org/10.1002/j.1556-6678.2009.tb00130.x

Greijdanus, H., de Matos Fernandes, C. A., Turner-Zwinkels, F., Honari, A., Roos, C. A., Rosenbusch, H., \& Postmes, T. (2020, 2020/10/01/). The psychology of online activism and social movements: relations between online and offline collective action. Current Opinion in Psychology, 35, 49-54. https://doi. org/10.1016/j.copsyc.2020.03.003

Hu, L., \& Bentler, P. M. (1998). Fit indices in covariance structure modeling: Sensitivity to underparameterized model misspecification. Psychological Methods, 3(4), 424-453. https://doi.org/10.1037/1082989X.3.4.424

Hu, L., \& Bentler, P. M. (1999). Cutoff criteria for fit indexes in covariance structure analysis: Conventional criteria versus new alternatives. Structural Equation Modeling: A Multidisciplinary Journal, 6(1), 1-55. https://doi.org/10.1080/10705519909540118

Igielnik, R., \& Budiman, A. (2020). The changing racial and ethnic composition of the U.S. electorate. Retrieved from https://www.pewresearch.org/2020/09/23/the-changing-racial-and-ethnic-composition-of-the-u$\underline{\text { s-electorate/ }}$ 
Iyer, A., Leach, C. W., \& Crosby, F. J. (2003). White guilt and racial compensation: The benefits and limits of self-focus. Personality and Social Psychology Bulletin, 29(1), 117-129. https://doi. org/10.1177/0146167202238377

Jones, V. (2016). It's Time for \#JusticeReformNOW. Retrieved from https://www.change.org/p/tell-congress-its-time-for-justicereformnow

Jost, J. T., Becker, J., Osborne, D., \& Badaan, V. (2017). Missing in (collective) action: Ideology, system justification, and the motivational antecedents of two types of protest behavior. Current Directions in Psychological Science, 26(2), 99-108. https://doi.org/10.1177/0963721417690633

Kim, G. S., Kahn, V. D., Tawa, J., \& Suyemoto, K. L. (2017). Toward a ripple effect: Psychologists collaborate in social justice education at a high school. Journal for Social Action in Counseling and Psychology, 9(2), 112-131. https://doi.org/10.33043/JSACP.9.2

Kozlowski, C., Ferrari, J., \& Odahl, C. (2014). Social justice and faith maturity: Exploring whether religious beliefs impact civic engagement. Education, 134(4), 427-432. https://doi.org/ eric. ed.gov/?id=EJ1034979

Kuo, A., Malhotra, N., \& Mo, C. H. (2017). Social exclusion and political identity: The case of Asian American partisanship. The Journal of Politics, 79(1), 17-32. https://doi.org/10.1086/687570

Kwon, S. A. (2008). Moving from complaints to action: Oppositional consciousness and collective action in a political community. Anthropology \& Education Quarterly, 39(1), 59-76. https://doi.org/10.1111/j.15481492.2008.00005.x

Lang, C. (2020). The Asian American response to black lives matter is part of a long, complicated history. Time. Retrieved from https://time.com/5851792/asian-americans-black-solidarity-history/

Le, T. K., Cha, L., Han, H.-R., \& Tseng, W. (2020). Anti-Asian xenophobia and Asian American COVID-19 disparities. American Journal of Public Health, 110(9), 1371-1373. https://doi.org/10.2105/ ajph.2020.305846

Lewis, J. A., Neville, H. A., \& Spanierman, L. B. (2012). Examining the influence of campus diversity experiences and color-blind racial ideology on students' social justice attitudes. Journal of Student Affairs Research and Practice, 49(2), 119-136. https://doi.org/10.1515/jsarp-2012-6291

Lin, M. (2020). From alienated to activists: expressions and formation of group consciousness among Asian American young adults. Journal of Ethnic and Migration Studies, 46(7), 1405-1424. https://doi.org/10.1 $\underline{080 / 1369183 X .2018 .1495067}$

Mallinckrodt, B., Abraham, W. T., Wei, M., \& Russell, D. W. (2006). Advances in testing the statistical significance of mediation effects. Journal of Counseling Psychology, 53(3), 372-378. https://doi. org/10.1037/0022-0167.53.3.372

Malott, K. M., Schaefle, S., Paone, T. R., Cates, J., \& Haizlip, B. (2019). Challenges and coping mechanisms of whites committed to antiracism. Journal of Counseling \& Development, 97(1), 86-97. https://doi. org/10.1002/jcad.12238

Martín-Baró, I., Aron, A., \& Corne, S. (1994). Writings for a liberation psychology. Cambridge, MA: Harvard University Press.

McEachan, R. R. C., Conner, M., Taylor, N. J., \& Lawton, R. J. (2011). Prospective prediction of health-related behaviours with the theory of planned behaviour: A meta-analysis. Health Psychology Review, 5(2), $97-$ 144. https://doi.org/10.1080/17437199.2010.521684 
Mele, C. (2016). Online petitions take citizen participation to new levels. But do they work? The New York Times. Retrieved from https://www.nytimes.com/2016/12/28/us/online-petitions-activism.html

Meredith, W. (1993). Measurement invariance, factor analysis and factorial invariance. Psychometrika, 58(4), 525-543. https://doi.org/10.1007/bf02294825

Muthén, B., du Toit, S. H. C., \& Spisic, D. (1997). Robust inference using weighted least squares and quadratic estimating equations in latent variable modeling with categorical and continuous outcomes. Muthén \& Muthén. http://www.statmodel.com/bmuthen/articles/Article 075.pdf

Muthén, L., \& Muthén, B. (1998-2015). Mplus user's guide (7th ed.). Muthén \& Muthén.

Napolitano, C. M., \& Job, V. (2018). Assessing the implicit theory of willpower for strenuous mental activities scale: Multigroup, across-gender, and cross-cultural measurement invariance and convergent and divergent validity. Psychological Assessment, 30(8), 1049-1064. https://doi.org/10.1037/pas0000557

Neal, S. (2017, August 29). Views of racism as a major problem increase sharply, especially among Democrats. Pew Research Center. Retrieved from http://www.pewresearch.org/fact-tank/2017/08/29/views-ofracism-as-a-major-problem-increase-sharply-especially-among-democrats/

Neville, H., Spanierman, L., \& Doan, B. T. (2006). Exploring the association between color-blind racial ideology and multicultural counseling competencies. Cultural Diversity and Ethnic Minority Psychology, 12(2), 275-290. https://doi.org/10.1037/1099-9809.12.2.275

Pillen, H., McNaughton, D., \& Ward, P. R. (2020). Critical consciousness development: a systematic review of empirical studies. Health Promotion International, 35(6), 1519-1530. https://doi.org/10.1093/heapro/ $\underline{\text { daz125 }}$

Prilleltensky, I. (2012). Wellness as fairness. American Journal of Community Psychology, 49(1-2), 1-21. https:// doi.org/10.1007/s10464-011-9448-8

Ratts, M. J., Singh, A. A., Butler, S. K., Nassar-McMillan, S., \& McCullough, J. R. (2016). Multicultural and social justice counseling competencies: Practical applications in counseling. Counseling Today. Retrieved March 25, 2020, from https://ct.counseling.org/2016/01/multicultural-and-social-justicecounseling-competencies-practical-applications-in-counseling/

Rise, J., Kovac, V., Kraft, P., \& Moan, I. S. (2008). Predicting the intention to quit smoking and quitting behaviour: Extending the theory of planned behaviour. British Journal of Health Psychology, 13(2), 291310. https://doi.org/doi:10.1348/135910707X187245

Ruiz, N. G., Horowitz, J. M., \& Tamir, C. (2020). Many Black and Asian Americans say they have experienced discrimination amid the COVID-19 outbreak. Pew Research Center. https://www.pewsocialtrends. org/2020/07/01/many-black-and-asian-americans-say-they-have-experienced-discrimination-amidthe-covid-19-outbreak/

Samson, F. L. (2015). Racial resentment and smoking. Social Science \& Medicine, 126, 164-168. https://doi. org/10.1016/j.socscimed.2014.12.033

Shih, K. Y., Chang, T. F., \& Chen, S. Y. (2019). Impacts of the model minority myth on Asian American individuals and families: Social justice and critical race feminist perspectives. Journal of Family Theory \& Review, 11(3), 412-428. https://doi.org/10.1111/jftr.12342

Shin, R. Q., Ezeofor, I., Smith, L. C., Welch, J. C., \& Goodrich, K. M. (2016). The development and validation of the contemporary critical consciousness measure. Journal of Counseling Psychology, 63(2), 210-223. https://doi.org/10.1037/cou0000137 
Tabachnick, B. G., \& Fidell, L. S. (2013). Using multivariate statistics (6th ed.). Boston, MA: Allyn \& Bacon/ Pearson Education.

The Fairness Project. (2016). Stand with us to fight for a higher minimum wage. Retrieved from https://www. change.org/p/stand-with-us-to-fight-for-a-higher-minimum-wage

The New York Times. (2018). 11 killed in synagogue massacre; suspect charged with 29 counts. Retrieved from https://www.nytimes.com/2018/10/27/us/active-shooter-pittsburgh-synagogue-shooting.html

Torres-Harding, S. R., Siers, B., \& Olson, B. D. (2012). Development and psychometric evaluation of the Social Justice Scale (SJS). American Journal of Community Psychology, 50(1-2), 77-88. https://doi.org/10.1007/ s10464-011-9478-2

Vandenberg, R. J., \& Lance, C. E. (2000). A review and synthesis of the measurement invariance literature: Suggestions, practices, and recommendations for organizational research. Organizational Research Methods, 3(1), 4-70. https://doi.org/10.1177/109442810031002

Watts, R. J., Diemer, M. A., \& Voight, A. M. (2011). Critical consciousness: Current status and future directions. New Directions for Child and Adolescent Development, 2012(134), 43-57. https://doi. org/10.1002/cd.310

Watts, R. J., \& Flanagan, C. (2007). Pushing the envelope on youth civic engagement: A developmental and liberation psychology perspective. Journal of Community Psychology, 35(6), 779-792. https://doi. org/10.1002/jcop.20178

Watts, R. J., Griffith, D. M., \& Abdul-Adil, J. (1999). Sociopolitical development as an antidote for oppression-theory and action. American Journal of Community Psychology, 27(2), 255-271. https:// doi.org/10.1023/A:1022839818873

Watts, R. J., \& Guessous, O. (2006). Sociopolitical development: The missing link in research and policy on adolescents. In S. Ginwright, P. Noguera, \& J. Cammarota (Eds.), Beyond Resistance! Youth Activism and Community Change: New Democratic Possibilities for Practice and Policy for America's Youth (pp. 59-80). New York, NY: Routledge.

Watts, R. J., Williams, N. C., \& Jagers, R. J. (2003). Sociopolitical development. American Journal of Community Psychology, 31(1-2), 185-194. https://doi.org/10.1023/A:1023091024140

Weston, R., \& Gore, P. A. (2006). A brief guide to structural equation modeling. The Counseling Psychologist, 34(5), 719-751. https://doi.org/10.1177/0011000006286345

White, K. M., Terry, D. J., Troup, C., Rempel, L. A., Norman, P., Mummery, K., Riley, M., Posner, N., \& Kenardy, J. (2012). An extended theory of planned behavior intervention for older adults with type 2 diabetes and cardiovascular disease. Journal of Aging and Physical Activity, 20(3), 281-299. https://doi. org/10.1123/japa.20.3.281

Wray-Lake, L., \& Tang, J. (2016). Are they political? Examining asian american college students' civic engagement. Asian American Journal of Psychology, 8(1), 31-42. https://doi.org/10.1037/aap0000061

Yi, J., \& Todd, N. R. (2020). Social change behaviors among Asian American college students: Ethnic regional group differences and campus-level predictors. Asian American Journal of Psychology, 11(4), 211-222. https://doi.org/10.1037/aap0000204 